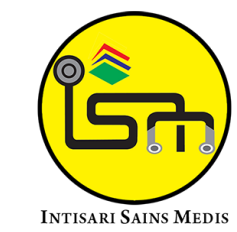

Published by Intisari Sains Medis

\section{Adverse skin reactions of healthcare workers using N95 mask and latex gloves at Kasih Ibu Denpasar General Hospital Bali Indonesia during coronavirus disease 2019 (COVID-19) pandemic - a descriptive study}

\author{
Firly Clarissa Suyanto ${ }^{1 *}$, Ariana ${ }^{2}$, Ni Made Dwi Puspawati ${ }^{3}$
}

'Faculty of Medicine, Universitas Udayana, Bali, Indonesia;

2Dematology and Venereology Department, Kasih Ibu General Hospital, Denpasar, Bali, Indonesia; ${ }^{3}$ Dermatology and Venereology Department, Faculty of Medicine, Universitas Udayana-Sanglah General Hospital, Bali, Indonesia;

*Corresponding author:

Firly Clarissa Suyanto;

Faculty of Medicine, Universitas Udayana, Bali, Indonesia;

firly13@yahoo.com

Received: 2021-04-08

Accepted: 2021-06-25

Published: 2021-07-01

\section{ABSTRACT}

Introduction: Corona virus disease 2019 (COVID-19), caused by SARS-CoV-2, was first identified in Wuhan, Hubei Province, China in December 2019. World Health Organization (WHO) then officially declared the disease as a global pandemic in March 2020. It has rapidly spread throughout the world, causing a huge burden to the health sector. With the increasing number of cases, healthcare workers (HCWs) were exposed to the regular use of personal protective equipment (PPE) such as N95 masks, latex gloves, and gowns. As a result of long term use of PPE, many adverse skin reactions may occur. Hence, this study aims to determine the adverse skin reactions among healthcare workers using PPE.

Method: This study is a cross-sectional descriptive study conducted at Kasih Ibu Denpasar General

Hospital Bali Indonesia. Questionnaires were used for the research. A total of 45 valid questionnaires were collected, with the majority being women (88.9\%) and with an age range of $20-30$ years old (55.6\%).

Result: The result showed that the most common adverse skin reactions among HCWs wearing N95 masks were indentation and ear pain (73.3\%) and nasal bridge scarring (48.9\%). The most common adverse skin reactions among $\mathrm{HCWs}$ wearing latex gloves were dry skin (46.7\%) and skin soaked with sweat (17.8\%). Conclusion: Our study explored the adverse skin reactions due to long term use of PPE, N95 mask and latex gloves in particular. These adverse skin reactions are mostly mild because they continue using PPE.

Keywords: adverse skin reactions, healthcare workers, latex gloves.

Cite This Article: Suyanto, F.C., Ariana., Puspawati, N.M.D. 2021. Adverse skin reactions of healthcare workers using $N 95$ mask and latex gloves at Kasih Ibu Denpasar General Hospital Bali Indonesia during coronavirus disease 2019 (COVID-19) pandemic - a descriptive study. Intisari Sains Medis 12(2): 705-707. D0I: 10.15562/ism.v12i2.1052

\section{INTRODUCTION}

In the last 2 decades, there have been 3 coronaviruses that are very pathogenic and deadly to humans, namely SARS-CoV, MERS-CoV, and SARS-CoV-2. SARS$\mathrm{CoV}-2$ is the latest coronavirus detected in Wuhan, Hubei Province, China in December 2019. The World Health Organization announced the disease caused by SARS-CoV-2 as Corona Virus Disease 2019 (COVID-19). It was then declared as a global pandemic in March 2020. At present, COVID-19 has spread speedily throughout the world, causing a huge burden specifically on health sector. ${ }^{1}$

According to WHO, globally, 17 million confirmed cases and 680.000 people died per August 2020. The first COVID-19 case in Indonesia began in March 2021. Over the subsequent 7 months, there were 11.472 deaths from 315.714 affected. These data suggest that the number of patients infected with SARS-CoV-2 was much higher than the number infected with SARS-CoV in 2002-2003 and MERS$\mathrm{CoV}$ in 2012, indicating the infection rate per exposure is higher. ${ }^{2}$

As a consequence of the rapid transmission of COVID-19, healthcare workers (HCWs) were at significant risk of acquiring the disease and for that reason, personal protective equipment (PPE) should be worn. PPE, such as N95 mask, latex glove, and gown, would often be worn for hours at a time. Few studies have shown adverse skin reactions related to the long-term use of PPE by HCWs. ${ }^{1,3}$ Nonetheless, existing research on adverse skin reactions due to long term use of PPE by HCWs in Indonesia is still limited. This study gathered the results of adverse skin reactions caused by N95 mask and latex gloves by HCWs at Kasih Ibu Denpasar General Hospital Bali Indonesia during COVID-19 pandemic. Our purpose was to determine the prevalence and characteristics of adverse skin reactions to N95 masks and latex gloves among HCWs, thus decide whether long term use of PPE results in significant occupational 
health risks.

\section{MATERIALS AND METHOD}

This research used descriptive research with a cross-sectional approach to determine the prevalence and characteristics of adverse skin reactions due to the use of PPE by HCWs at Kasih Ibu Denpasar General Hospital Bali Indonesia during COVID-19 Pandemic. The target population chosen for this study was HCWs at Kasih Ibu Denpasar General Hospital Bali Indonesia who met the inclusion and exclusion criteria. Inclusion criteria were HCWs of all ages with adverse skin reactions due to N95 mask and latex gloves during COVID-19 pandemic at Kasih Ibu Denpasar General Hospital Bali Indonesia. Exclusion criteria were HCWs of all ages without adverse skin reactions due to N95 mask and latex gloves during COVID-19 pandemic at Kasih Ibu Denpasar General Hospital Bali Indonesia.

Samples were obtained from questionnaires distributed online. The questionnaires included the demographic data of participants (gender and age) and adverse skin reactions due to the use of N95 masks and latex gloves. Data processing was carried out using Microsoft Excel and presented the proportion and percentages in tables.

\section{RESULTS}

A total of $45 \mathrm{HCWs}$ responded to the questionnaire. Among them, there were 5 men $(11.1 \%)$ and 40 women (88.9\%). The majority of them were within an age range of 20 - 30 years old (55.6\%). These HCWs are described in Table 1.

\section{Masks}

All healthcare workers (100\%) who used N95 masks regularly reported adverse skin reactions, with indentation and ear pain $(73.3 \%)$ being in the majority. Nasal bridge scarring (48.9\%) was the second most common adverse skin reaction and followed by acne (33.3\%), rash (20\%), dry skin (15.6\%), and facial itching (15.6\%). These reactions may overlap as one participant may have more than one adverse skin reaction. All those with reactions developed them while using

Table 1. Demographical characteristics of the participants

\begin{tabular}{lccc}
\multicolumn{2}{c}{ Characteristics } & Number & $\%$ \\
\hline Gender & & & \\
& Man & 5 & $11.1 \%$ \\
\multirow{4}{*}{ Age } & Woman & 40 & $88.9 \%$ \\
& $20-30$ & & \\
& $30-40$ & 25 & $55.6 \%$ \\
& $40-50$ & 14 & $31.1 \%$ \\
& $50-60$ & 5 & $11.1 \%$ \\
& & 1 & $2.2 \%$ \\
\hline
\end{tabular}

Table 2. Adverse skin reactions of using N95 mask

\begin{tabular}{ccc}
\hline $\begin{array}{c}\text { Adverse Skin Reactions By Using A } \\
\text { Mask* }\end{array}$ & $\mathbf{n}$ & $\%$ \\
\hline Indentation and ear pain & 33 & $73.3 \%$ \\
Nasal bridge scarring & 22 & $48.9 \%$ \\
Acne & 15 & $33.3 \%$ \\
Rash & 9 & $20 \%$ \\
Dry skin & 7 & $15.6 \%$ \\
Facial itching & 7 & $15.6 \%$ \\
\hline
\end{tabular}

${ }^{*}$ with overlaps

Table 3. Adverse skin reactions of using latex gloves

\begin{tabular}{ccc}
\hline $\begin{array}{c}\text { Adverse Skin Reactions By Using The } \\
\text { Gloves* }\end{array}$ & $\mathbf{n}$ & $\%$ \\
\hline Dry skin & 21 & $46.7 \%$ \\
Skin soaked with sweat & 8 & $17.8 \%$ \\
Itching & 4 & $8.9 \%$ \\
Rash & 2 & $4.4 \%$ \\
\hline
\end{tabular}

${ }^{\star}$ with overlaps

N95 masks for an average of 8 hours per day and over a mean of 8 months. HCWs who used surgical masks and cloth masks did not report any adverse skin reactions. Table 2 lists all the adverse skin reactions reported. Due to high transmission of COVID-19, all 45 HCWs proceeded to use N95 masks despite their symptoms. None of them seeked professional treatment nor self-medicated.

\section{Gloves}

Of 45 HCWs who used latex gloves regularly, 26 (57.7\%) reported adverse skin reactions, including dry skin $(46.7 \%)$, skin soaked with sweat (17.8\%), itching (8.9\%), and rash (4.4\%). These reactions may overlap as one participant may have more than one adverse skin reaction. Those who developed reactions were using latex gloves for an average 3.9 hours a day over a mean period of 8 months. Table 3 lists all the adverse skin reactions of using latex gloves reported by HCWs. All of them continued to use latex gloves despite their symptoms. None of them seeked professional treatment nor self-medicated.

\section{DISCUSSION}

As a consequence of highly contagious effects of COVID-19, HCWs who work for suspected or confirmed patients are required to wear PPE, such as N95 mask, latex gloves, and protective clothing. N95 mask is made of polypropylene fabric and must fit perfectly against the face for it to work effectively. ' $\mathrm{N}$ ' stands for NIOSH the National Institute for Occupational Safety and Health of the USA, while '95' signifies its filter efficiency. As a result, the mask has a 95\% filtration efficiency in filtering particles with a size of $\geq 300 \mathrm{~nm}$. SARS-CoV-2 diameter is between $80-120$ $\mathrm{nm}$, but it will be wrapped in saliva to 
form larger droplets when expelled from patients. $^{4,5}$

Numerous studies have demonstrated the adverse skin reactions of long term use of N95 masks. Hu et al., reported the most common adverse skin reactions were nasal bridge scarring and facial itching. ${ }^{5}$ While Foo et al., described acne and facial itching were the most common. ${ }^{4}$ In this study, we found that the most common adverse skin reaction of N95 mask usage was indentation and ear pain, followed by nasal bridge scarring and acne. Owing to the fact that healthcare workers must have adequate protection, they will tie the mask tightly. Thus, indentation and ear pain and nasal bridge scarring may occur because of the excessive pressure of the mask and the hardness of the metal clip. ${ }^{2}$ Possible 5 reasons may cause acne. First, the hot and humid environment created in areas of the face covered by the mask could result in acne flare-up. Secondly, local pressure on the skin from tight masks could also predispose acne flare-ups. ${ }^{4}$

The use of medical gloves during a pandemic is crucial in the effort to limit the infection spread. Medical gloves are made from different materials, but nitrile and latex are more recommended during COVID-19 pandemic because they have better durability. Latex gloves are more commonly used because they are flexible, sensitive to touch and provide moderate protection. However, latex gloves have been reported to cause type I Immunoglobulin E-mediated latex hypersensitivity in some people. ${ }^{6}$ Some people may even have latex allergy or irritant contact dermatitis, which results from repeated handwashing with soap and detergent and not drying the hands completely. Thus, the inside of the glove will not be able to absorb water, resulting in irritation. ${ }^{4,5}$ Symptoms of skin reactions to latex gloves included dry skin, itch, and rash. ${ }^{5}$ In this study, we found that the most common adverse skin reactions due to long term use of latex gloves were dry skin, followed by itching, and skin soaked with sweat.

\section{CONCLUSION}

Our study explored the adverse skin reactions due to long term use of PPE, N95 mask and latex gloves in particular. These adverse skin reactions are primarily mild because they continue using PPE. However, the reported skin reactions could not be verified by professionals because they were purely based on subjective assessment of HCWs themselves. Nonetheless, this study may be useful to HCWs in the future as COVID-19 infection worldwide remains uncontrollable.

\section{DISCLOSURE}

\section{Ethical consideration}

This study uses online data, and personal consent from individuals is obtained through online signatures from respondents to agree to fill out an online survey.

\section{Conflict of interest}

All authors declare there is no conflict of interest regarding publication of this study.

\section{Funding}

None.

\section{Author contribution}

Firly Clarissa Suyanto and Ariana responsible for data gathering, analysis, brainstorming, and project administration. Ni Made Dwi Puspawati responsible methodological guidance and supervision

\section{REFERENCES}

1. Kakodkar P, Kaka N, Baig MN. A Comprehensive Literature Review on the Clinical Presentation, and Management of the Pandemic Coronavirus Disease 2019 (COVID-19). Cureus. 2020;12(4):e7560-e7560. Available from: https://pubmed.ncbi.nlm.nih. gov/32269893

2. Guo G, Ye L, Pan K, Chen Y, Xing D, Yan K, et al. New Insights of Emerging SARS-CoV-2: Epidemiology, Etiology, Clinical Features, Clinical Treatment, and Prevention. Front cell Dev Biol. 2020;8:410. Available from: https:// pubmed.ncbi.nlm.nih.gov/32574318

3. Gheisari M, Araghi F, Moravvej H, Tabary M, Dadkhahfar S. Skin reactions to nonglove personal protective equipment: an emerging issue in the COVID-19 pandemic. J Eur Acad Dermatol Venereol. 2020/06/17. 2020;34(7):e297-8. Available from: https:// pubmed.ncbi.nlm.nih.gov/32302444

4. Foo CCI, Goon ATJ, Leow Y-H, Goh C-L. Adverse skin reactions to personal protective equipment against severe acute respiratory syndrome--a descriptive study in Singapore. Contact Dermatitis. 2006;55(5):291-4. Available from: https://pubmed.ncbi.nlm.nih. gov/17026695

5. Hu K, Fan J, Li X, Gou X, Li X, Zhou X. The adverse skin reactions of health care workers using personal protective equipment for COVID-19. Medicine (Baltimore). 2020;99(24):e20603-e20603. Available from: https://pubmed.ncbi.nlm.nih.gov/32541493

6. Tabary M, Araghi F, Nasiri S, Dadkhahfar S. Dealing with skin reactions to gloves during the COVID-19 pandemic. Infect Control Hosp Epidemiol. 2020/05/08. 2021;42(2):247-8. Available from: https://pubmed.ncbi.nlm.nih. gov/32381129

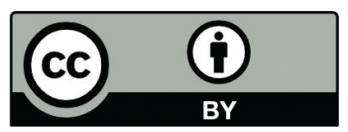

This work is licensed under a Creative Commons Attribution 